Article

\title{
Influence of Adding Offcuts and Trims with a Recycling Approach on the Properties of High-Density Fibrous Composites
}

\author{
Conrad M. Sala ${ }^{1,2}$, Eduardo Robles ${ }^{3}\left[\right.$ and Grzegorz Kowaluk ${ }^{1, *}$ (i) \\ 1 Department of Technology and Entrepreneurship in Wood Industry, Warsaw University of Life \\ Sciences-SGGW, Nowoursynowska St. 159, 02-776 Warsaw, Poland; conrad_sala@sggw.edu.pl \\ 2 Chief Technologist, IKEA Industry Poland sp. z o. o. brand Orla, Koszki 90, 17-106 Orla, Poland \\ 3 Institute of Analytical and Physicochemical Sciences for the Environment and Materials (IPREM-UMR 5254), \\ CNRS/Univ Pau \& Pays Adour/E2S UPPA, IUT of the Pays de l'Adour, 371 Rue du Ruisseau, \\ 40004 Mont de Marsan, France; eduardo.robles@univ-pau.fr \\ * Correspondence: grzegorz_kowaluk@sggw.edu.pl; Tel.: +48-22-59-38-546
}

Received: 27 May 2020; Accepted: 5 June 2020; Published: 10 June 2020

\begin{abstract}
The sizeable global production of wood-based products requires new sources of raw material, but also creates large quantities of wastes or composites that do not comply with requirements. In this study, the influence of different shares of recovered high-density fiberboards (HDF-r), reversed into the production, on industrial HDF properties, has been examined. HDF-r may be a suitable partial substitute for raw pinewood for industrial HDF production. Although most of the mechanical properties, as well as thickness swelling and water absorption, had a linear decrease with the increase in the share of HDF-r share, the elaborated boards met most of the commercial requirements (EN 622-5). The property that did not meet the requirements was the internal bond strength for panels with $10 \%$ of HDF-r. The presented results show that, after some adjustments, it should be possible to produce HDF boards with up to $10 \%$ of recycled HDF being able to meet all commercial requirements.
\end{abstract}

Keywords: fibers; recycling; wood; mechanical properties; physical properties; strength

\section{Introduction}

Global development and population growth [1] result in a more significant demand for new space for accommodation. Due to that fact, there is also a growing need for building materials, not only bricks or plasterboards, but also wood-based panels, for example, oriented strand boards (OSB), plywood, or insulation boards, including soft boards (SB) or low-density fiberboards (LDF). Together with the operation new residential buildings, the demand for new furniture made of, for example, particleboards (PB) or fiberboards, among which the most common are hardboard (HB), medium-density fiberboards (MDF), and high-density fiberboards (HDF), is growing as well. For this reason, there has been a considerable growth in the world production of wood-based panels. Figure 1 presents how the world production of wood-based panels has increased from 124 million $\mathrm{m}^{3}$ in 1990 to over 405 million $\mathrm{m}^{3} 2018$ [2].

The primary material for the production of wood-based panels is wood itself. Based on the data shown in Figure 1, it can be seen that the world production of coniferous pulpwood, round wood, and split wood has grown from 266 million $\mathrm{m}^{3}$ in 2000 to over 351 million $\mathrm{m}^{3}$ in 2018 [2]. The price increase of the raw materials has supposed a struggle for the furniture industry [3]. In Poland, in 2018, a significant jump (39.2\%) in the price of building materials was observed, in particular for wood and wood-based panels [4], on which wood price had an influence as well. Different wood species are used for the production of wood-based panels, depending on their availability. The species of Polish forest consists of $\approx 70 \%$ of pine (Pinus sylvestris L.), and $\approx 6 \%$ of oak (Quercus robur L.), spruce (Picea abies (L.) 
H. Karst.) and birch (Betula pendula Roth) each [5]. For this reason, pine and spruce wood are the most used materials for the production of MDF, while alder (Alnus glutinosa (L.) Gaertn.), birch, and beech (Fagus sylvatica L.) wood are used rarely [6]. The average price of pinewood, reported by Polish State Forests, has increased by about 15\% from $\$ 53 \mathrm{~m}^{-3}$ in the period 2013-2017 [7]. This situation requires academia and industry within the wood-based products to investigate and develop new sources of raw material or its substitutes. Not only sawdust, but yearly-available straws or plastics (for wood plastic composites-WPC) may be used for board production. Also, recovered wood and recovered $\mathrm{PB}$ and MDF boards may be treated and used as a substitute for raw wooden material for the boards production [8].

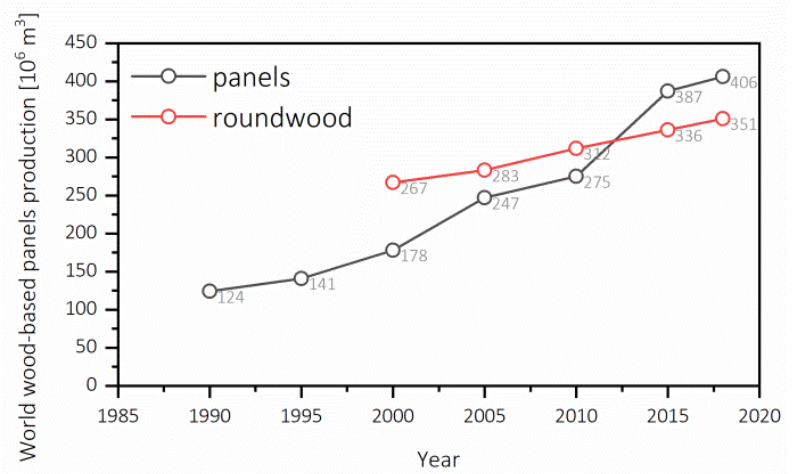

Figure 1. World wood-based panels production 1990-2018 and World pulpwood, round and split, coniferous production 2000-2018 (own elaboration according to [2]).

Particleboards are the most common wood-based products currently used in recycled wooden materials for their production (WRAP, www.nottinghamshire.gov.uk) [9]. Previous work has explored the production of medium density particleboards (MDP) with wood waste from construction and demolition [10]. As an example, Yang (2007) [11] studied the use of recycled wood-waste chips for the production of particleboards for use in kitchens, bathrooms, as a flooring material, and in outdoor equipment. Moreover, Laskowska \& Mamiński in 2018 showed that it is possible to substitute $20-100 \%$ of virgin material with post-industrial plywood [12]. In another work, the addition of $30-50 \%$ of recovered MDF into PB production was proven possible but with adverse influences on the mechanical and physical properties of the final products [13].

Similarly to particleboards, it is possible to reintroduce wood waste fibrous material when producing fiberboards. Previous works have explored the elaboration of insulation fiberboards, as soft boards (SB) [14] using recovered fibers. Another work has elaborated hardboard (HB) made of recycled corrugate cardboard [15], reintroducing 20\% of recovered MDF for dry-process MDF production, where panels meet the requirements of relevant standard requirements [16]. Furthermore, to reduce wood wastes disposed of in landfills, MDF can be produced from up to 100\% recovered fibers, or even of old newsprint fibers $[17,18]$. Also, there are suggestions to re-use the post-used MDF fibers in MDF production after their steam refining conversion [19]. This approach sounds to be more reasonable than the deeper processing of the MDF recovered fibers to bioethanol production [20]. However, these MDF end-of-life scenarios also should be applied instead of landfills.

Although the recycling of wooden materials is environmentally friendly [8], the recovered fiber pulp has different chemical and physical characteristics when compared to virgin fibers [21]. These differences affect the final mechanical and physical properties of the fiberboards negatively [20]. Due to that fact, the process requires an optimization of the production parameters to obtain the best features of fiberboards produced with waste panels returned into the production as a raw material. Moreover, to achieve this, the physical and mechanical properties of reversed materials must be known [22]. Fibers produced from waste wood material, such as particleboards, OSB, and MDF, are suitable and may be used as secondary raw material for the production of fiberboards [23]. In this 
sense, the examination of fibers recovered from fiberboards can be a useful tool for assessing the potential properties of recycled fiberboards [24].

According to data provided by FAO (Food and Agriculture Organization) [2], the production of fiberboards (MDF and HDF) in Poland increased nearly five times over the last 20 years from $768,000 \mathrm{~m}^{3}$ in 2000 to over $3,600,000 \mathrm{~m}^{3}$ in 2018 . One of the most significant impacts on this growth was the opening of ultrathin HDF production lines, such as Kronospan in 2003 [25], Homanit Karlino in 2005, Homanit Krosno Odrzańskie in 2015 [26], Pfleiderer Grajewo in 2007 [27], and Ikea Industry Orla in 2011 [28]. This increase was a response of wood-based panels producers to increasing demand for HDF boards used in honeycomb construction doors as skins or for furniture production in board-on-frame construction (BOF) [29]. As a conclusion drawn from the information above, the HDF production market in Poland is developing very fast. An increasing wood price caused by an increasing need for wooden material from new wood-based panel factories, as well as the availability [30] of suitable recovered material for fiberboard production, results in the need to evaluate the influence of the share of HDF-r on the final properties of industrial HDF.

The goal of this investigation was to determine the influence of the different amount of recovered HDF on the mechanical properties of industrial high-density fiberboard, such as modulus of rupture, modulus of elasticity, internal bond, and surface soundness, but also on physical properties such as thickness swelling, surface water absorption, surface roughness, and formaldehyde content, as well as on surface color.

\section{Materials and Methods}

\subsection{Materials}

Virgin pine (Pinus sylvestris L.) debarked round wood from Polish State Forests (Podlaskie voivodeship, Poland) was used to produce the fiberboards. Virgin fibers were produced on industrial Metso Defibrator EVO56 (Metso, Helsinki, Finland) with a $2.5 \mathrm{~m}$ diameter disc with ten knives. Recovered HDF (HDF-r) came from internal HDF production reject, such as offcuts from side trimming saws and leftovers from the process board breaker, these shredded HDF were mixed with virgin chips in the feeding conveyor of the defibrillator. Raw boards used for this investigation as a target were $2.5 \mathrm{~mm}$ HDF with an aimed density of $860 \mathrm{~kg} \mathrm{~m}^{-3}$, and compelled with CARB 2 standard of formaldehyde content.

\subsection{Elaboration of HDF}

Four different mass shares of recovered HDF were examined: $2 \%, 5 \%, 10 \%$, and $20 \%$. Wood chips or a mix of shredded HDF-r and wood chips were treated under constant hydrothermal parameters. Briefly, a preheating pressure of $0.94 \mathrm{MPa}$ at $180{ }^{\circ} \mathrm{C}$ for $3.2 \mathrm{~min}$ with average defibrating energy consumption of $145 \mathrm{kWh} \mathrm{t}^{-1}$, giving an average bulk density of $\approx 22.15 \mathrm{~kg} \mathrm{~m}^{-3}$. A paraffin emulsion was added to the defibrillator containing $0.5 \%$ of dry paraffin calculated on the weight of the oven-dried fibers. Fibers were glued on a blow-line system with high-steam pressure using a commercial melamine-urea-formaldehyde (MUF) resin with a melamine content of $5.2 \%$, molar ratio of 0.89 , and solid content of $66.5 \%$. The resination was set at $11 \%$ of dry resin calculated on dry fibers with $21 \%$ of urea addition and $3.0 \%$ of ammonium nitrate hardener, both calculated regarding dry resin content. The final moisture content of the fibrous mat after drying and before the pressing was $\approx 10.5 \%+/-$ $0.3 \%$. All boards were pressed with constant parameters on an industrial Dieffenbacher continuous press system with a $5.3 \mathrm{~s} \mathrm{~mm}^{-1}$ press factor.

\subsection{Adjustment of HDF-r Dosage}

To control the proper amount of HDF-r being added into the production of HDF production, the screw feeder was loaded with HDF offcuts and leftovers. Different settings of maximum rotation per minute were put into the controller: $0 \%, 0.3 \%, 1 \%, 2 \%, 3 \%, 5 \%$, and $8 \%$. The amount of fed HDF-r 
particles was weighted each hour, and based on the moisture content, dry tons per hour were calculated for each setting. Based on those measurements, an average feeding capacity was determined and referred to a constant defibrillator capacity of $30 \mathrm{tat} \mathrm{h}^{-1}$ (dry-tons per hour). For further analysis, setting on the screw feeding controller for dosing HDF-r. The elaborated HDF had a content of $0 \%$ (V0), 2\% (V2), 5\% (V5), 10\% (V10), and 20\% (V20) of HDF-r.

\subsection{Raw Material Fraction}

The fraction of pine chips and HDF-r particles was examined with an IMAL vibrating laboratory sorter with nine sieves. The selected sieve sizes were $40,20,10,8,5,3.15,1,0.315$, and $<0.315 \mathrm{~mm}$. The amount of material for each fraction was $\approx 100 \mathrm{~g}$, and the set time of continuous vibrating was $5 \mathrm{~min}$. Gathered results were shown as an average of three examinations.

\subsection{Fibers Fraction}

A fraction of fibers produced with different HDF-r share was examined with an ALPINE Air Jet Sieve e200LS (Hosokawa Alpine AG, Augsburg, Germany), according to DIN 66165. Six sieves in the sizes of 125, 315, 630, 1000, 1600, and $2500 \mu \mathrm{m}$ were used. Five grams of each fiber fraction was analyzed; the sieving time was set at $2 \mathrm{~min}$. Gathered results are shown as an average of three examinations.

\subsection{HDF Examination}

All the elaborated HDF were conditioned at $20^{\circ} \mathrm{C}$, an test specimens were cut accordingly to EN-326-2 [31] and EN-326-1 [32]. The moduli of rupture (MOR) and elasticity (MOE) were determined according to EN 310 [33], internal bond (IB) was determined according to EN 319 [34], and surface soundness (SS) was determined according to EN 311 [35]. All the mechanical properties were examined with an IB700 (IMAL) laboratory-testing machine (Imal s.r.l., San Damaso, Italy). Board density was determined according to EN 323 on the IB700 testing machine (Imal s.r.l., San Damaso, Italy), moisture content according to EN 322, and thickness swelling (TS) due to EN 317 [36] while surface water absorption due to EN 382-1 [37]. The test of surface roughness was performed with a Surtronic 25 equipment (Taylor Hobson, Leicester, England) and results are an average from 10 measurements. The density profiles of the HDF were measured on a GreCon DAX 5000 device (Fagus-GreCon Greten $\mathrm{GmbH} \&$ Co. KG, Alfeld/Hannover, Germany) [38]. Board formaldehyde content was examined according to EN 12460-5 [39] with a Hach-Lange (HACH LANGE GmbH, Duesseldorf, Germany) spectrophotometer. A Konica Minolta (Konica Minolta Co., Ltd, Tokio, Japan) CM-700d/600d unit was used to define HDF surface color according to the CIELab color system. For each board type, as many as ten samples were analyzed.

\subsection{Statistical Analysis}

Analysis of variance (ANOVA) and t-tests calculations were used to test $(\alpha=0.05)$ for significant differences between factors and levels, where appropriate, using IBM SPSS statistic base (IBM, SPSS 20, Armonk, NY, USA). A comparison of the means was performed when the ANOVA indicated a significant difference by employing the Duncan test.

\section{Results}

The results of the sieving are shown in Table 1. As it could be noticed, the fraction of pine chips was according to the requirements. The sieving of HDF-r particles was comparable to virgin pine chips, but some differences in sieves 2 and 3 could be noticed. There was about $38 \%$ less material on sieve 2 , which resulted in not meeting the requirements. On the other hand, there was $24 \%$ more material on sieve 3 .

Figure 2 presents a visual assessment of virgin pine chips and shredded HDF particles. The first visible difference is the color, with HDF-r being darker than wood chips. These color differences might 
be caused by the hydrothermal treatment during the defibrating process, but also by the caramelization of simple sugars (pentoses and hexoses) during pressing operation [6].

Table 1. Sieving results for pine and spruce wood chips.

\begin{tabular}{cccccccccc}
\hline Sieve & $\mathbf{1}^{\mathbf{a}}$ & $\mathbf{2}^{\mathbf{b}}$ & $\mathbf{3}^{\mathbf{c}}$ & $\mathbf{4}^{\mathbf{d}}$ & $\mathbf{5}^{\mathbf{e}}$ & $\mathbf{6}^{\mathbf{e}}$ & $\mathbf{7}^{\mathbf{f}}$ & $\mathbf{8}^{\mathbf{f}}$ & $\mathbf{9}^{\mathbf{f}}$ \\
\hline Size [mm] & 40 & 20 & 10 & 8 & 5 & 3.15 & 1 & 0.315 & $<0.315$ \\
\hline Pine chips [\%] & 0.74 & 51.80 & 39.19 & 4.64 & 3.07 & & 0.56 \\
Recycled HDF [\%] & 0.55 & 32.48 & 52.50 & 4.67 & 4.15 & & 0.50 & \\
\hline
\end{tabular}

Requirements: ${ }^{\mathrm{a}}<1 \%,{ }^{\mathrm{b}} 45 \%<{ }^{\mathrm{c}} 35 \%<{ }^{\mathrm{d}}<5 \%,{ }^{\mathrm{e}}<8 \%,{ }^{\mathrm{f}}<1 \%$.
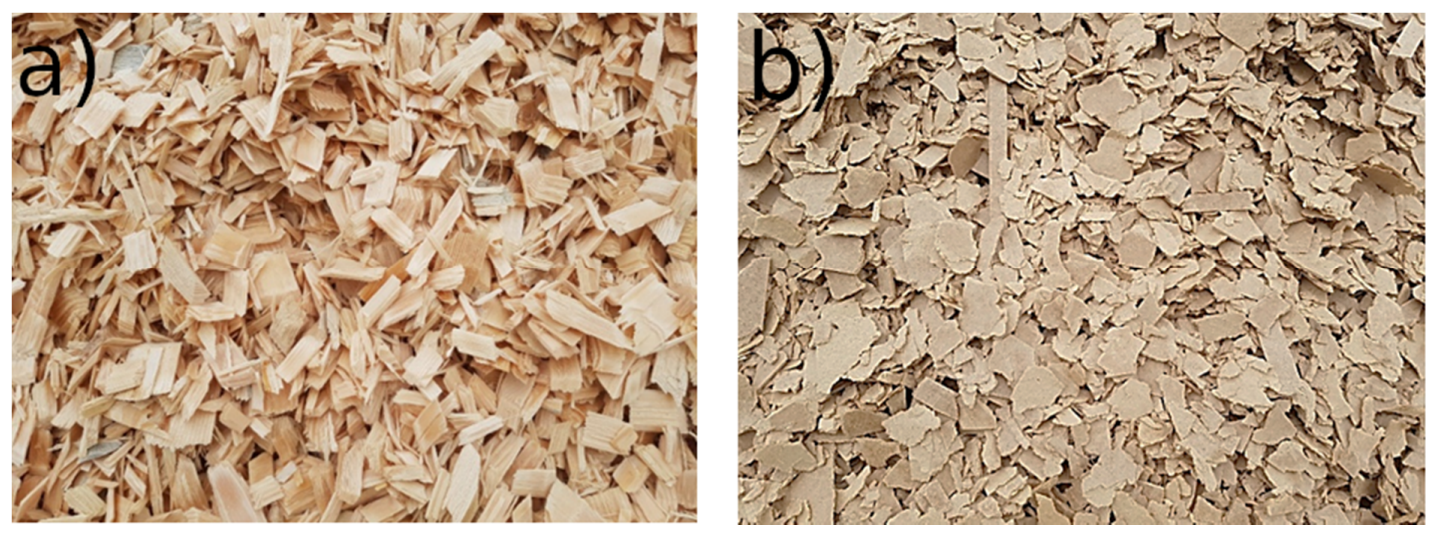

Figure 2. Pictures of produced chips: virgin pine (a) and HDF-r (b).

Although the parameters of the defibrator were kept constant, the bulk density of the fibers differed, as shown in Table 2. Properties of wood fibers as length, distribution, and bulk density have an important influence [40] and depend on a proper defibration. Results in Table 2 show the bulk density measurement of the different fibrous masses with various content of HDF-r. Fibers produced from virgin pine chips had the lowest bulk density compared to those with different HDF-r share. V0 had $18.75 \mathrm{~kg} \mathrm{~m}^{-3}$, while the addition of $2 \%$ of HDF-r caused an increase in the bulk density of $\approx 11 \%$ to $21.15 \mathrm{~kg} \mathrm{~m}^{-3}$. An increase in the HDF-r share to $5 \%$ caused additional growth in the bulk density of $\approx 9 \%$ (up to $23.31 \mathrm{~kg} \mathrm{~m}^{-3}$ ). The bulk density then stabilizes, as the difference between 5 and $10 \%$ is minimal. In comparison, the addition of $20 \%$ HDF-r slightly increased the bulk density to $24.20 \mathrm{~kg} \mathrm{~m}^{-3}$, which represents an increase of less than $4 \%$ when compared with the bulk density of fibers having a $10 \%$ HDF-r share.

Table 2. Fibers bulk density for panels.

\begin{tabular}{cccccc}
\hline Sample & V0 & V2 & V5 & V10 & V20 \\
\hline $\begin{array}{c}\text { Fiber bulk density } \\
{\left[\mathrm{kg} \mathrm{m}^{-3}\right]}\end{array}$ & 18.75 & 21.15 & 23.31 & 23.33 & 24.20 \\
\hline
\end{tabular}

Fibers were analyzed with a fiber-sieving device before the elaboration of composite panels; the results of mass share [\%] of different fractions are shown in Table 3. The sieve retaining the majority of the fibers was $125 \mu \mathrm{m}$, the percent of fibers retained in this sieve was comparable for V0, V2, and V5, while the lowest value on this sieve was in V10 (60.3\%). The main difference can be appreciated on the second sieve $(315 \mu \mathrm{m})$ in which the number of fibers on sieve size was decreasing with the addition of HDF-r. While V0 had a share of $27 \%$, V10 had $17.7 \%$, representing 34 percentage points less. On the other hand, the sum of fibers from sieves 630,1000,1600, and $2500 \mu \mathrm{m}$ was increasing as the share of HDF-r increased. The total amount of fibers from V0 on the last four sieves was $9.5 \%$, while for V2, V5, 
and V10, it was $11.6 \%, 15.82 \%$, and $21.63 \%$, accordingly. As can be seen, the share of fibers in larger sieves for V10 was more than double compared to V0. This might influence the final properties of the HDF. Since HDF boards produced from fibers with a $20 \%$ share of HDF-r had many blisters (steam blows in the middle of the thickness of the panels) during production, they could not be examined. For this reason, they were automatically diverted into the board breaker by an online GreCon UPU blister detection sensor.

Table 3. Fractions share of tested fibers mass.

\begin{tabular}{ccccc}
\hline \multirow{2}{*}{ Sieve Size $[\mu \mathrm{m}]$} & \multicolumn{3}{c}{ Variant } \\
\cline { 2 - 5 } & V0 & V2 & V5 & V10 \\
\hline $\mathbf{1 2 5}$ & 63.5 & 63.6 & 62.2 & 60.3 \\
$\mathbf{3 1 5}$ & 27.0 & 24.8 & 21.8 & 17.7 \\
$\mathbf{6 3 0}$ & 7.9 & 6.6 & 8.6 & 9.3 \\
$\mathbf{1 0 0 0}$ & 1.4 & 3.6 & 4.8 & 9.2 \\
$\mathbf{1 6 0 0}$ & 0.2 & 1.3 & 2.4 & 3.1 \\
$\mathbf{2 5 0 0}$ & 0.0 & 0.1 & 0.2 & 0.4 \\
\hline
\end{tabular}

The HDF surface color differences have been determined according to the CIELab color system [41]. The results are shown in Figure 3. For this analysis, V0 was used as the reference. According to Commission Internationale de l'Eclairage (CIELab), an important parameter in comparing and analyzing color is $\Delta \mathrm{E}$, as it tells about how much the color of the tested sample differs from the standard [42]. In this sense, all tested boards produced with HDF-r addition had noticeable $(\Delta \mathrm{E}>5)$ color difference compared to V0. The main aspect was that the addition of HDF-r made the surface darker. The brightest surface was V0, with an $\mathrm{L}$ value of 67.96 . The biggest difference could be seen for V2 $(\Delta \mathrm{E}=8.56)$, and this was related to a more reddish $(\Delta \mathrm{a}=1.75)$ and yellow $(\Delta \mathrm{b}=3.92)$ color compared to V0. The lowest color difference is that of $\mathrm{V} 10(\Delta \mathrm{E}=5.30)$, although the difference was $7 \%$ darker. The surface of the $\mathrm{V} 0$ had an increase in red $(\Delta \mathrm{a}=1.47)$ and blue $(\Delta \mathrm{b}=1.58)$ spectra. $\mathrm{V} 5$ varied from V0 $(\Delta \mathrm{E}=5.36)$. However, it was comparable to V10. Moreover, V5 changed minimally to a shade of red $(\Delta \mathrm{a}=1.54)$ and blue $(\Delta \mathrm{b}=1.37)$.
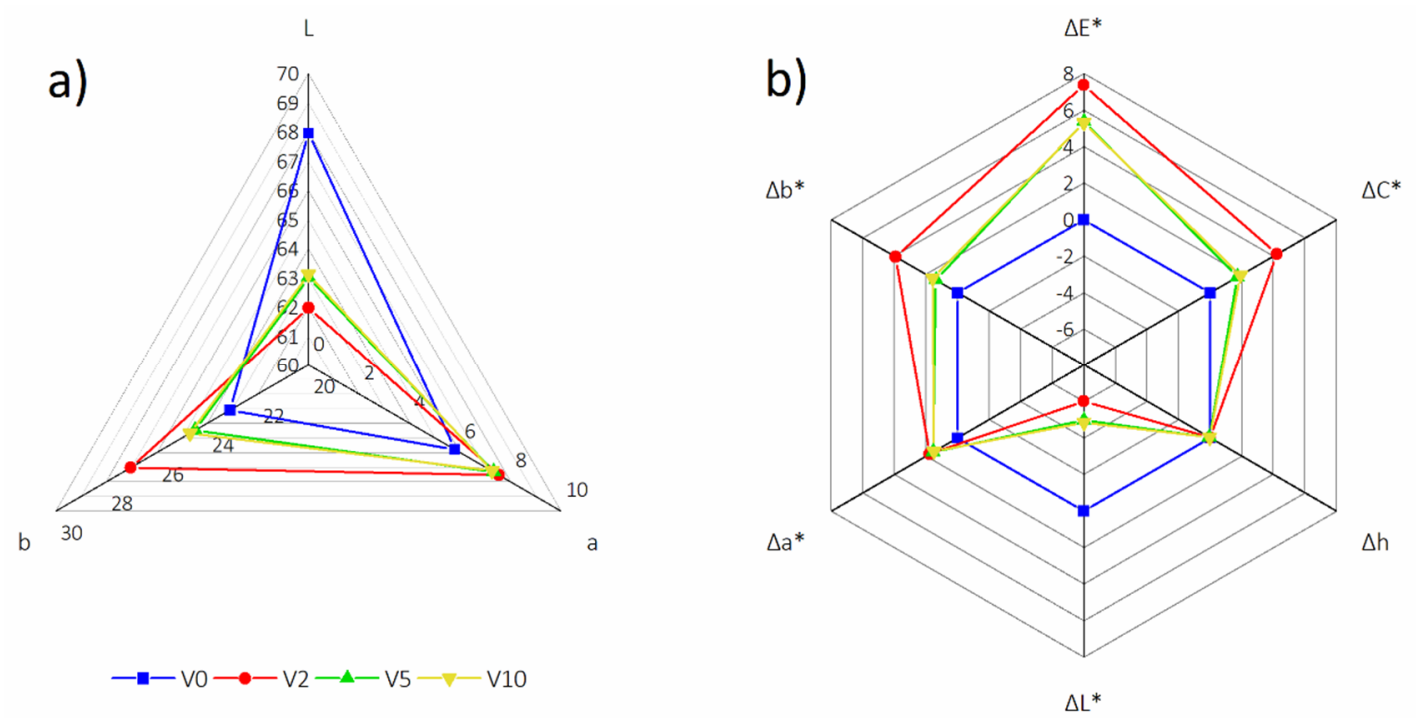

Figure 3. HDF color analysis: L, a and b parameters (a) and E, C, h, L, a and b changes $(\Delta)(\mathbf{b})$.

The density profile distribution was characterized, and the results are shown in Figure 4. The density of the top side of the board is on the left side of the pictures, and the bottom side surface 
density is on the right side. The difference between the top and bottom surface density was relatively small, and it was for about $2-3 \%$ lower for the bottom side.

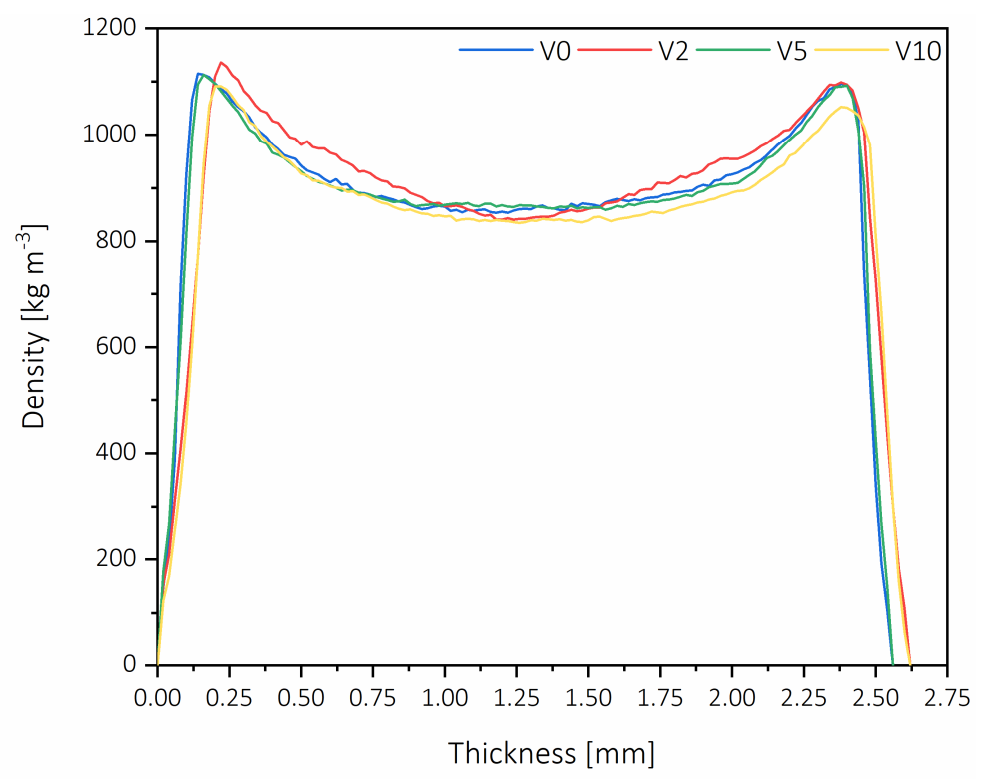

Figure 4. Vertical density profiles of tested HDF panels.

All the examined density profiles were similar and characteristic for HDF panels; moreover, from these figures, it can be observed that there was no delamination of the HDF. Figure 5 shows the average maximum surface density (ASD) and the average minimum core density (ACD). The highest ASD was obtained for V2 $\left(1136 \mathrm{~kg} \mathrm{~m}^{-3}\right)$, while the lowest ACD was obtained for V10 and V2, being 840 and $841 \mathrm{~kg} \mathrm{~m}^{-3}$ accordingly. The biggest difference between ASD and ACD was observed for V2. Additionally, similar to the lowest ACD, the minimum ASD was obtained for V10 $\left(1091 \mathrm{~kg} \mathrm{~m}^{-3}\right)$, which is $4 \%$ less than the maximum. The difference between ASD and ACD for V0 was $262 \mathrm{~kg} \mathrm{~m}^{-3}$, while for $\mathrm{V} 5$, it was $5 \%$ lower and gave the smallest difference in density profile $\left(249 \mathrm{~kg} \mathrm{~m}^{-3}\right)$. The ASD of V5 was comparable to that of V0 and was on the level of $1114 \mathrm{~kg} \mathrm{~m}^{-3}$. It is worth noticing that not only the surface and core densities influence the properties of fiberboards properties, but also the difference between those two parameters [43].

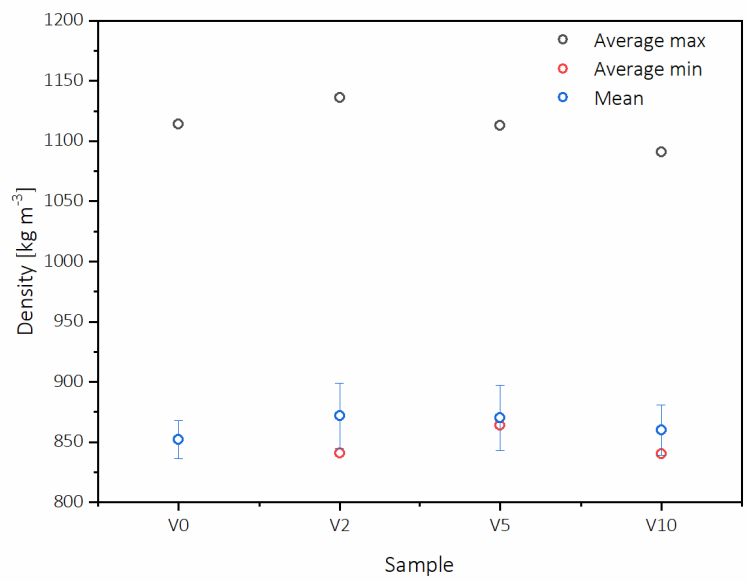

Figure 5. HDF boards average maximum surface density and average minimum core density.

Bending strength results are shown in Figure 6. V0 had a modulus of rupture (MOR) of $55.8 \mathrm{~N} \mathrm{~mm}^{-2}$ with a density of $852 \mathrm{~kg} \mathrm{~m}^{-3}$, which is within EN 622-5 requirements (grey line level on Figure 6) of the average density tolerance of $860 \mathrm{~kg} \mathrm{~m}^{-3}+/-7 \%$ [44]. Panel properties such as MOE and 
MOR are positively affected by an increase in density [45]. However, having higher moisture content affects those properties negatively [46]. Although V2 had MOR comparable to V0 $\left(55.8 \mathrm{~N} \mathrm{~mm}^{-2}\right)$, its density $\left(872 \mathrm{~kg} \mathrm{~m}^{-3}\right)$ was $20 \mathrm{~kg} \mathrm{~m}^{-3}$ higher, this might have influenced the final MOR result. In particular, the highest surface density $\left(1136 \mathrm{~kg} \mathrm{~m}^{-3}\right)$ might have affected. Additionally, the moisture content of V2 (5.29\%) was more than six percentage points higher than V0 (5.63\%), which, according to Ganev et al. [46], might have also influenced the result.
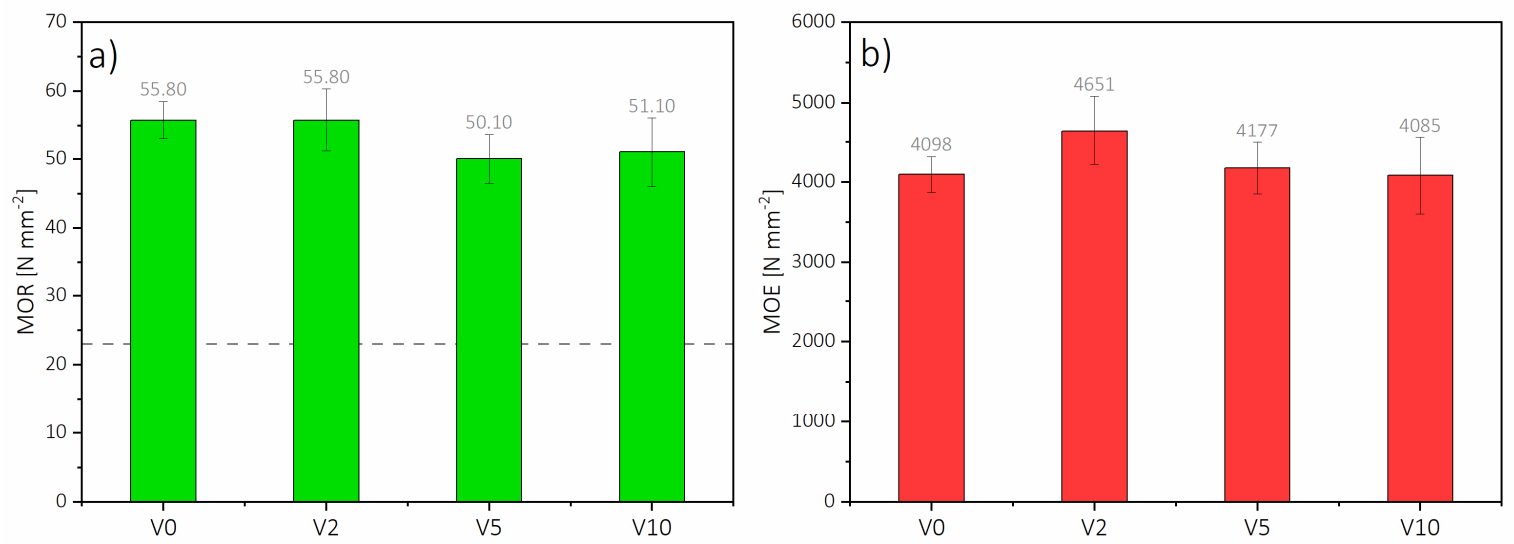

Figure 6. (a) HDF Modulus of rupture (MOR), and (b) Modulus of Elasticity (MOE).

On the other hand, considering that V2 and V5 have almost the same density $\left(870 \mathrm{~kg} \mathrm{~m}^{-3}\right)$ and similar panel moisture content, the decrease of bending strength of $\mathrm{V} 5$ for about $10 \%$ is related to the content of HDF-r. However, further increase of HDF-r, as in V10, did not result in further MOR value decrease. When analyzing MOR results statistically (Table 4), it should be pointed out that there are no statistically significant differences between the mean values of the MOR results. All of the tested HDF have met the requirements of EN 622.

Table 4. Statistical analyses results ( $p$-values).

\begin{tabular}{|c|c|c|c|c|c|c|c|}
\hline MOR & V2 & V5 & V10 & MOE & V2 & V5 & V10 \\
\hline V0 & 0.287 & 0.067 & 0.078 & V0 & 0.052 & 0.115 & 0.287 \\
\hline V2 & & 0.286 & 0.081 & V2 & & 0.064 & 0.073 \\
\hline V5 & & & 0.242 & V5 & & & 0.279 \\
\hline IB & V2 & V5 & V10 & SS & V2 & V5 & V10 \\
\hline V0 & $0.004^{*}$ & 0.046 & 0.003 & V0 & 0.056 & 0.119 & 0.268 \\
\hline V2 & & $\overline{0.282}$ & $\overline{0.276}$ & V2 & & 0.054 & 0.051 \\
\hline V5 & & & 0.084 & V5 & & & 0.243 \\
\hline TS $2 \mathrm{~h}$ & V2 & V5 & V10 & TS $24 \mathrm{~h}$ & V2 & V5 & V10 \\
\hline V0 & 0.254 & 0.058 & 0.046 & V0 & 0.057 & 0.061 & 0.029 \\
\hline V2 & & 0.069 & $\overline{0.064}$ & V2 & & 0.124 & $\overline{0.138}$ \\
\hline V5 & & & 0.199 & V5 & & & 0.035 \\
\hline
\end{tabular}

* enhanced values indicate statistically significant differences.

Regarding MOE, the highest was that of V2 $\left(4651.4 \mathrm{~N} \mathrm{~mm}^{-2}\right)$, and the lowest was that of V10 $\left(4085.0 \mathrm{~N} \mathrm{~mm}^{-2}\right)$. V2 and V5 had accordingly $12 \%$ and $2 \%\left(4177.3 \mathrm{~N} \mathrm{~mm}^{-2}\right)$ higher modulus of elasticity values compared to V0 $\left(4097.7 \mathrm{~N} \mathrm{~mm}^{-2}\right)$. These values could be explained by the density of those boards, but on the other hand, within the same range of densities, there is a drop of MOE for V 5 compared to V2 of more than $10 \%$. Increasing the amount of HDF-r reduces the fiber coverage with the resin and consequently affects the mechanical properties [18]. Another factor affecting the mechanical properties is bulk density [47]. According to statistical analysis, it should be pointed out that there are no statistically significant differences between the mean values of the MOE results. 
Results for the internal bond (IB) of the HDF are presented in Figure 7. As it can be seen, not all the panels met the requirements for HDF stated at EN 622-5 (grey line level on Figure 7a), which demands IB to be above $0.65 \mathrm{~N} \mathrm{~mm}^{-2}$. While V0 had an IB of $1.15 \mathrm{~N} \mathrm{~mm}^{-2}$, the mean IB of panels with HDF-r was significantly lower. The lowest IB was obtained for V10 $\left(0.61 \mathrm{~N} \mathrm{~mm}^{-2}\right)$, and it was nearly $50 \%$ lower compared to $\mathrm{V} 0$, and $\approx 25 \%$ lower than V5 $\left(0.80 \mathrm{~N} \mathrm{~mm}^{-2}\right)$. Based on fiber bulk density and fiber analysis (Tables 2 and 3), such fibers may have a smaller particle size compared to HDF fibers from V0. The larger amount of fines increases the surface area of the fibers, which results in decreasing the resin coverage per unit surface area [48]. Hence, the strength of the final panel is lower. V2 obtained $15 \%$ lower IB $\left(0.67 \mathrm{~N} \mathrm{~mm}^{-2}\right)$ compared to V5, this might be caused by a difference in the density distribution on the profile. In V2, the average difference between ASD and ACD on the density profile was about $295 \mathrm{~kg} \mathrm{~m}^{-3}$, while in V5, it was: $249 \mathrm{~kg} \mathrm{~m}^{-3}$.
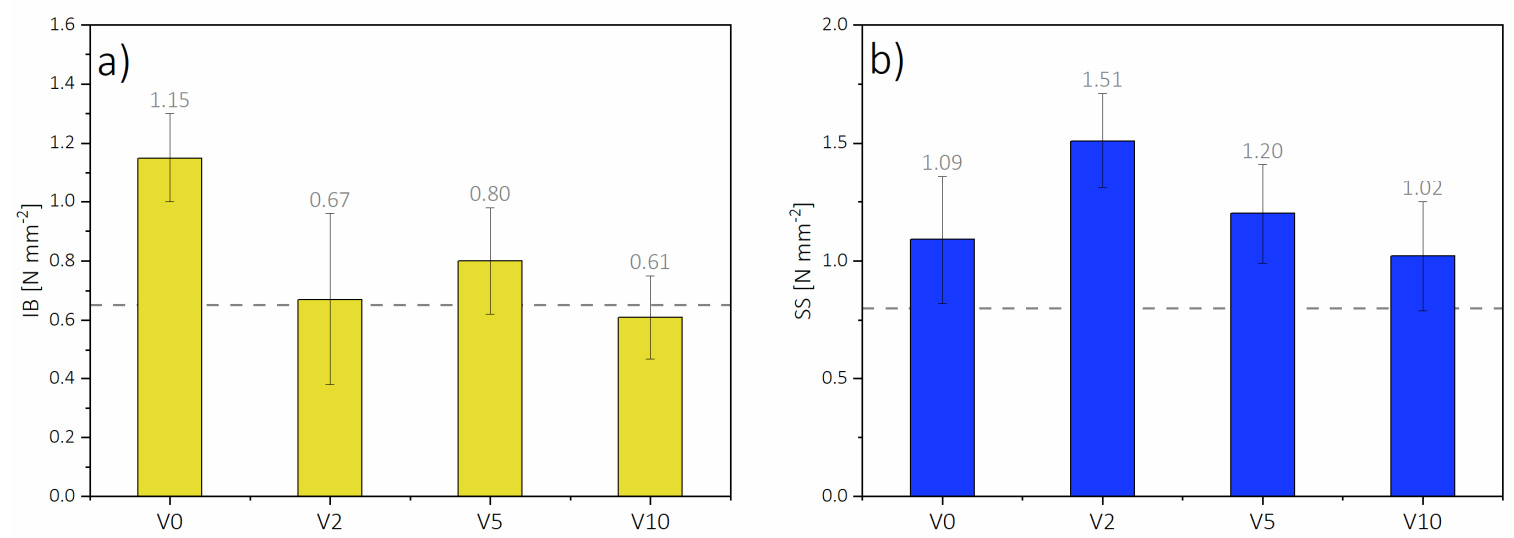

Figure 7. (a) Internal bond (IB) and (b) surface soundness (SS) results.

Moreover, V2 had a 3\% lower ACD than V5 $\left(864 \mathrm{~kg} \mathrm{~m}^{-3}\right)$. According to Wong, the IB of fiberboards is mostly determined by the core density and is not dependent on processing conditions [43]. Additionally, an increase in the share of HDF-r may decrease mechanical properties because of the way they are fibrillated and have a high fine fiber content [18]. The only statistically significant difference in mean values of IB has been found between V0 and the remaining panel types (Table 4).

Surface soundness (SS) was evaluated, for this, EN standards do not present any requirements, but typical industry requirement for SS is $>0.80 \mathrm{~N} \mathrm{~mm}^{-2}$ (grey line level on Figure $7 \mathrm{~b}$ ). Based on the results shown in Figure 7, it can be seen that the highest SS was obtained for V2 $\left(1.51 \mathrm{~N} \mathrm{~mm}^{-2}\right)$, and comparing to V0, which had a SS of $1.09 \mathrm{~N} \mathrm{~mm}^{-2}$, it was more than $27 \%$ higher. V5 had a $20 \%$ lower surface soundness $\left(1.20 \mathrm{~N} \mathrm{~mm}^{-2}\right)$ compared to $\mathrm{V} 2$, but nearly $10 \%$ higher than $\mathrm{V} 0$. The lowest SS was that of V10 $\left(1.02 \mathrm{~N} \mathrm{~mm}^{-2}\right)$, which was $\approx 32 \%$, lower than V2. While there is a direct relation between the bulk density of fibers and the mechanical properties of the MDF [49], there is an inversely proportional influence of the HDF-r share on SS. That might be caused by a worse quality of the recovered fibers as a consequence of their decrease in length (above $1711 \mu \mathrm{m}$ ) and also a significant increase in smaller fibers (with length 200-956 $\mu \mathrm{m}$ ) compared to virgin pine fibers [24]. There are no statistically confirmed differences between the mean values of the surface soundness of tested panels (Table 4).

The thickness swelling (TS) after 2 and $24 \mathrm{~h}$ values of HDF panels are displayed in Figure 8. The results for V0, V2, and V5 showed that TS2 and TS24 were dependent on the share of HDF-r, having a positive linear correlation. Wood, but also all wood-based products, shrink or swell depending on the moisture content of the material [50]. The relationships between shrinkage, swelling, and moisture content are roughly proportional [51], and there have been several reviews in the literature confirming that swelling of wood-based panels is decreasing with an increase of the moisture content [52]. For this reason, the minimum TS2 and TS24 could be noticed for V0, being $9.90 \%$ and $31.03 \%$, accordingly, while the moisture content of V0 was 5.63\%, which was the highest observed. The TS24 of V2 (32.82\%) increased $\approx 5 \%$ compared to V0, while V5 had an increase of $\approx 5 \%$ to $34.25 \%$. An increase in TS of 
panels with HDF-r might be caused by their rougher structure and their smaller dimensions compared to virgin fibers [21,24]. The highest TS2 and TS24 were measured for V10, being $11.71 \%$ and $34.54 \%$, respectively, which was $\approx 15 \%$ and $\approx 10 \%$ higher than $\mathrm{V} 0$. As can be seen, all the panels met the requirements for HDF stated at EN 622-5 (grey line level on Figure 8a). The only statistically significant differences between the achieved mean values of thickness swelling, both TS2 and TS24, have been confirmed between V0 and V10 (Table 4).
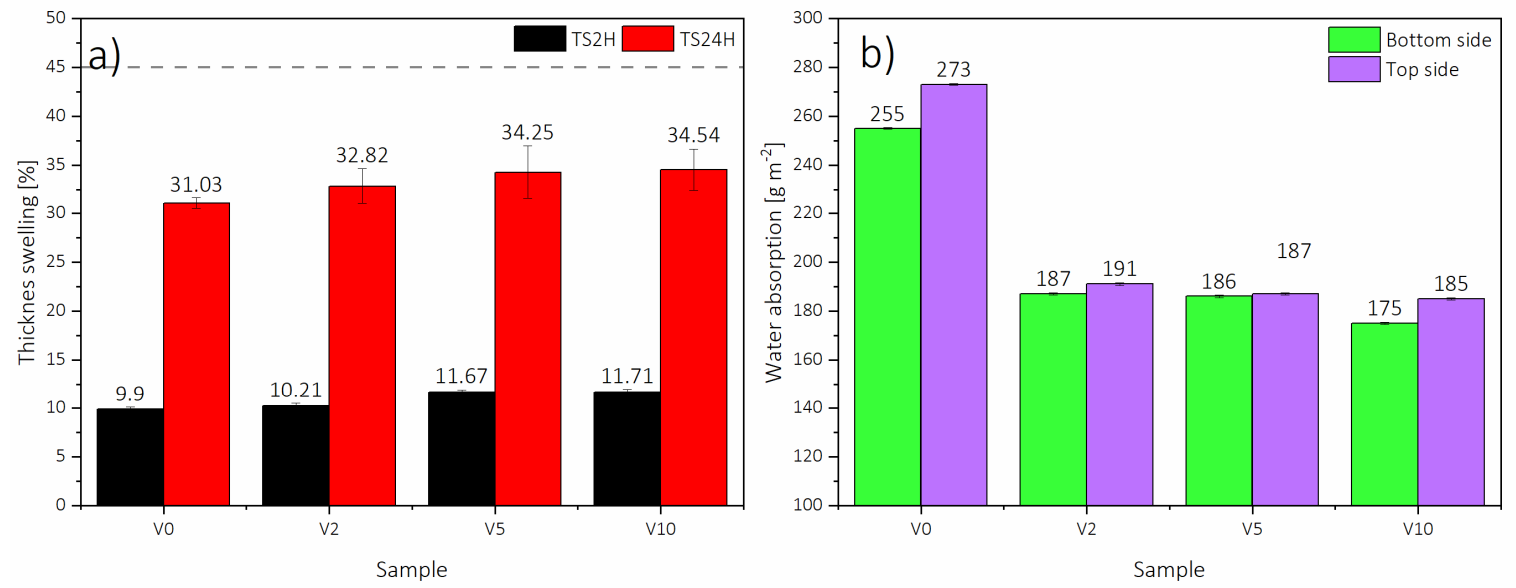

Figure 8. (a) HDF Thickness Swelling after $2 \mathrm{~h}$ and 24h, and (b) Surface Water Absorption (WA) in the top and bottom sides.

The surface water absorption (WA) was also examined. Although thickness swelling after $24 \mathrm{~h}$ was increasing with HDF-r share, reaching the highest value for V10 and the lowest for V0, the WA had the opposite trend. As can be seen in Figure 8, the highest WA for top and bottom HDF side was obtained for V0, accordingly, $255 \mathrm{~g} \mathrm{~m}^{-2}$ and $273 \mathrm{~g} \mathrm{~m}^{-2}$, while the lowest was for V10, with results of top side WA of $175 \mathrm{~g} \mathrm{~m}^{-2}$ and bottom side WA of $185 \mathrm{~g} \mathrm{~m}^{-2}$. All panels with HDF-r had $\approx 30 \%$ lower top $\left(\mathrm{V} 2=187 \mathrm{~g} \mathrm{~m}^{-2} ; \mathrm{V} 5=186 \mathrm{~g} \mathrm{~m}^{-2}\right)$ and bottom $\left(\mathrm{V} 2=191 \mathrm{~g} \mathrm{~m}^{-2} \mathrm{~V} 5=187 \mathrm{~g} \mathrm{~m}^{-2}\right)$ surface water absorption compared to V0, which is consistent with other works [21]. Moreover, in all panels, higher WA could be observed for the bottom side compared to the top side. For V0, it was 7\% higher, for V10, $5 \%$ higher, and $\mathrm{V} 2$ and $\mathrm{V} 5,1.5 \%$ higher as an average.

The surface roughness was examined since one of the factors influencing the consumption of sealing materials during lacquering is the roughness of the HDF surface, increasing together with the increase of the roughness [53]. Based on the results shown in Figure 8, the higher WA of HDF bottom side might be caused by a more closed surface (14\%) of the top side for all the panels, which had an average roughness of $3.09 \mu \mathrm{m}$, compared to an average roughness of the bottom side of $3.69 \mu \mathrm{m}$. This can be connected to a higher density of the top side layer, which was confirmed in the Figure 4 . Moreover, the lower surface roughness of panels produced with HDF-r could be caused by a higher fiber density compared to $\mathrm{V} 0$, which is easier to compress during the pressing process.

As it was mentioned, the panels were produced in compliance with CARB 2 standard. Therefore,

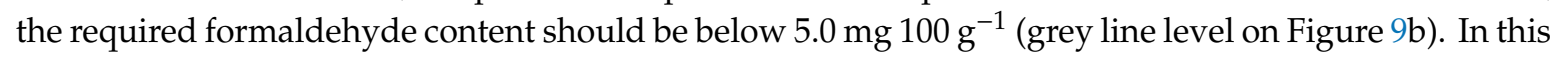
sense, not all the boards met that requirement being V2 and V 5 out of the CARB 2 specifications. As can

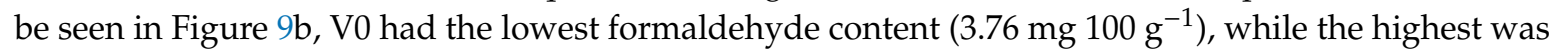

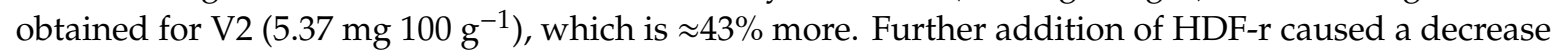
in formaldehyde content in V5 to $5.21 \mathrm{mg} 100 \mathrm{~g}^{-1}$ but still out of specification. However, V10 had the lowest result of formaldehyde content $\left(4.98 \mathrm{mg} 100 \mathrm{~g}^{-1}\right)$ from all the tested boards produced with HDF-r, which allowed meeting CARB 2 requirements. This decrease of formaldehyde content with an increase in the recycled share of fibers was also observed for MDF [21]. 

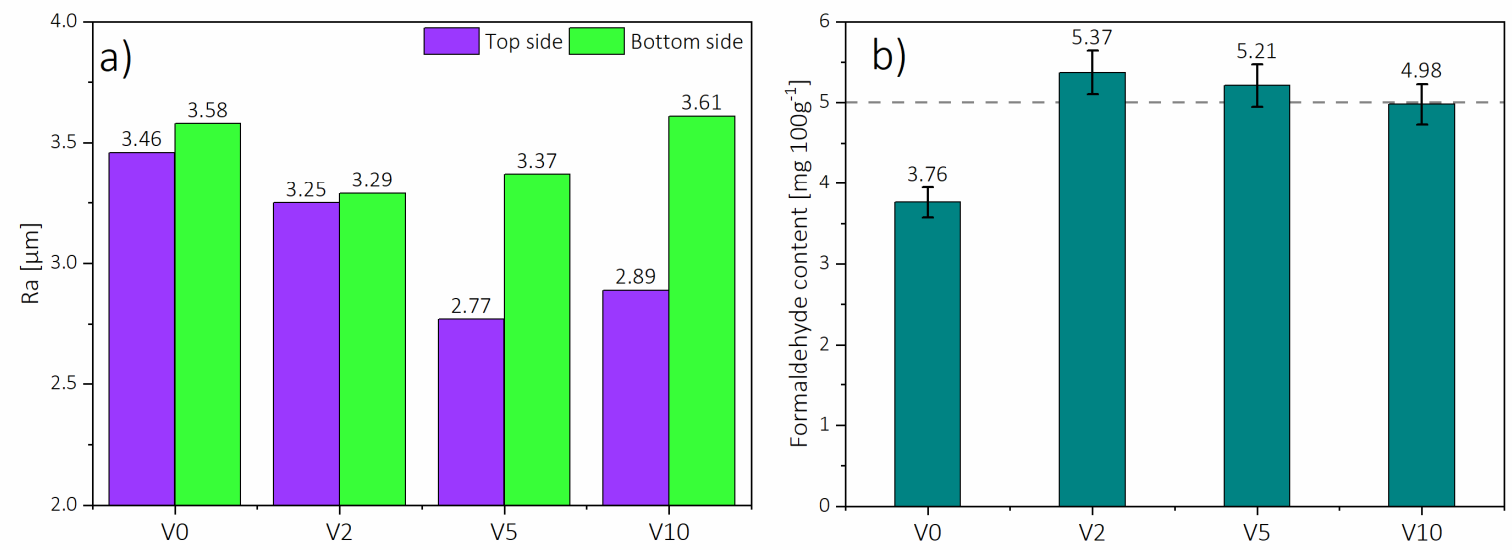

Figure 9. HDF surface roughness of top and bottom sides (a) and formaldehyde content of the elaborated HDF (b).

\section{Conclusions}

Recovered HDF is a suitable raw material substitute as a complement to virgin pine chips for industrial HDF production. It may be possible to produce industrial HDF with up to $10 \%$ HDF-r addition and meet EN 622-5 standard selected requirements. The surface of HDF produced with $2 \%$ HDF-r is significantly darker compared to those made of virgin pine wood. The addition of HDF-r caused an increase in fiber bulk density, which has an impact on the performance of HDF. Increasing the HDF-r share from $0 \%$ to $10 \%$ caused a decrease of MOR for about $9 \%$ while adding $2 \%$ of HDF-r caused an increase of MOE of $\approx 12 \%$, and further addition of HDF-r caused a slight decline of MOE. Increasing HDF-r share from $0 \%$ to $10 \%$ caused a decrease of internal bond for about $47 \%$, though these boards did not meet EN standard requirements. Implementation of $2 \%$ of HDF-r resulted in higher surface soundness for about $28 \%$, while a further increase of HDF-r to $10 \%$ caused a decrease of MOE of $\approx 6 \%$. The addition of HDF-r represented a $30 \%$ lower surface water absorption and about $12 \%$ lower surface roughness. An increase in the share of HDF-r represented an increase in the thickness swelling after $24 \mathrm{~h}$. The addition of HDF-r represented an increase of formaldehyde content, which might imply a reformulation of the bonding agent to meet with the CARB 2 standard.

Author Contributions: C.M.S. took part in designing the experiments and performed the experiments, analyzed the data, wrote the first draft of the paper, E.R. analyzed data statistically, wrote the final version of the paper, and G.K. designed the experiments, analyzed the data. All the authors assisted in writing and improving the paper. All authors have read and agreed to the published version of the manuscript.

Funding: Some of the mentioned tests have been completed within the activity of Student Furniture Research Group (Koło Naukowe Meblarstwa), Faculty of Wood Technology, Warsaw University of Life Sciences-SGGW. E.R. wants to thank the E2S UPPA Research Chair Partnership (BOIS) supported by the Excellence Initiative of the University of Pau and Pays de l'Adour and the I-Site E2S.

Acknowledgments: The authors would like to thank to IKEA Company, IKEA Industry Poland sp. z o. o. brand Orla, Koszki 90, 17-106 Orla, for ability to perform the tests in industrial scale.

Conflicts of Interest: The authors declare no conflict of interest.

\section{References}

1. Food and Agriculture Organization. Annual Population. Available online: http://www.fao.org/faostat/en/\# data/OA (accessed on 1 April 2020).

2. Food and Agriculture Organization. Forestry Production and Trade. Available online: http://www.fao.org/fa ostat/en/\#data/FO (accessed on 1 April 2020).

3. Kalinowska, D. Podwyżka Cen Mebli Przez Drogie Drewno [Furniture Price Increase through Expensive Wood (In Polish)]. Available online: https://www.rp.pl/artykul/864368-Podwyzka-cen-mebli-przez-drogie-d rewno.html (accessed on 1 April 2020). 
4. Jabłoński, D. Ceny Materiałów Drzewnych na Składach Budowlanych Poszybowały w Górę [Prices of Wood Materials in Building Depots Soared (In Polish)]. Available online: https://www.drewno.pl/artykuly/11132,cenymaterialow-drzewnych-na-skladach-budowlanych-poszybowaly-w-gore.html (accessed on 1 April 2020).

5. www.nadlesnictwo.pl Struktura polskich lasów [Structure of Polish forests (In Polish)]. Available online: http://www.nadlesnictwo.pl/str/struktura_lasow (accessed on 1 April 2020).

6. Nicewicz, D.; Sala, C.M. Technologiczne Aspekty Produkcji MDF [Technological Aspects of MDF Production (In Polish)]; Wydawnictwo SGGW: Warsaw, Poland, 2013; ISBN 9788375835120.

7. Jabłoński, D. Rekordowo Wysokie Ceny za Drewno w I Kwartale 2017 [Record High Prices for Wood in the First Quarter of 2017 (In Polish)]. Available online: https://www.drewno.pl/artykuly/10837,rekordowo-wys okie-ceny-za-drewno-w-i-kwartale-2017.html (accessed on 1 April 2020).

8. Oniśko, W. Nowe generacje tworzyw drzewnych i nowoczesne technologie [New generations of wood-based composites and modern technologies (In Polish)]. In Proceedings of the Drewnowizja, Instytut Technologii Drewna w Poznaniu, Poznań, Poland, 18 January 2011.

9. Types of Wood for Recycling. Available online: https://www.google.co.jp/url?sa=t\&rct=j\&q=\&esrc=s\&sour ce=web\&cd=\&ved=2ahUKEwjJ3oDSjPbpAhXXdd4KHUg-BgoQFjAKegQIBBAB\&url=https \%3A \%2F\%2 Fwww.nottinghamshire.gov.uk\%2Fplanningsearch\%2FDisplayImage.aspx\%3Fdoc\%3DcmVjb3JkX251b WJlcj01ODE2JmZpbGVuYW11PVxcbnMwMS0wMDI5XGZpbGVkYXRhMiRcREIwMy0wMDMwXFNoY XJlZEFwcHNcZGxnc1xwbGFuc1xwbGFubmluZ1xmLTI4NDhcMjU5MS1iIHdyYXAgd29vZCByZWN5Y 2xpbmcgZ3VpZGUucGRmJmltYWdlX251bWJlcj05JmltYWdlX3R5cGU9cGxhbm5pbmcmbGFzdF9tb2RpZ mllZF9mcm9tX2Rpc2s9MjUvMDYvMjAxMyAxNDoyOTozOQ\%3D\%3D\&usg=AOvVaw0qB87KG5zqub R0NtLOqnG7 (accessed on 1 April 2020).

10. da Azambuja, R.R.; de Castro, V.G.; Trianoski, R.; Iwakiri, S. Recycling wood waste from construction and demolition to produce particleboards. Maderas Cienc. Tecnol. 2018, 20, 681-690. [CrossRef]

11. Yang, T.H.; Lin, C.J.; Wang, S.Y.; Tsai, M.J. Characteristics of particleboard made from recycled wood-Waste chips impregnated with phenol formaldehyde resin. Build. Environ. 2007, 42, 189-195. [CrossRef]

12. Laskowska, A.; Mamiński, M. Properties of particleboard produced from post-Industrial UF-and PF-bonded plywood. Eur. J. Wood Wood Prod. 2018, 76, 427-435. [CrossRef]

13. Borysiuk, P.; Byczek, M.; Jenczyk-Tołłoczko, I.; Boruszewski, P.; Monder, S. An attempt to use postconsumer MDF as a raw material for the manufacture of particleboards. Ann. Warsaw Univ. Life Sci. SGGW For. Wood Technol. 2014, 87, 7-11.

14. Nicewicz, D.; Danecki, L. Recycling of insulation boards by reuse. Ann. Warsaw Univ. Life Sci. SGGW For. Wood Technol. 2010, 72, 57-61.

15. Hunt, J.F.; Vick, C.B. Strength and processing properties of wet-formed hardboards from recycled corrugated containers and commercial hardboard fibers. For. Prod. J. 1999, 49, 69-74.

16. Beele, P. Demonstration of End Uses for Recovered MDF Fibre; WRAP: Banbury, UK, 2009.

17. Runesson, U.T. Changing Look of Structural Wood. Available online: http://www.borealforest.org/panel/ (accessed on 1 April 2020).

18. Nourbakhsh, A.; Ashori, A.; Jahan-Latibari, A. Evaluation of the physical and mechanical properties of medium density fiberboard made from old newsprint fibers. J. Reinf. Plast. Compos. 2010, 29, 5-11. [CrossRef]

19. Hagel, S.; Saake, B. Fractionation of Waste MDF by Steam Refining. Molecules 2020, 25, 2165. [CrossRef] [PubMed]

20. Zhao, J.; Tian, D.; Shen, F.; Hu, J.; Zeng, Y.; Huang, C. Valorizing waste lignocellulose-Based furniture boards by phosphoric acid and hydrogen peroxide (Php) pretreatment for bioethanol production and high-Value lignin recovery. Sustainability 2019, 11, 6175. [CrossRef]

21. Lubis, M.A.R.; Hong, M.K.; Park, B.D.; Lee, S.M. Effects of recycled fiber content on the properties of medium density fiberboard. Eur. J. Wood Wood Prod. 2018, 76, 1515-1526. [CrossRef]

22. Wan, H.; Wang, X.M.; Barry, A.; Shen, J. Recycling wood composite panels: Characterizing recycled materials. BioResources 2014, 9, 7554-7565. [CrossRef]

23. Ihnát, V.; Lübke, H.; Russ, A.; Pažitný, A.; Borůvka, V. Waste agglomerated wood materials as a secondary raw material for chipboards and fibreboards part II. Preparation and characterisation of wood fibres in terms of their reuse. Wood Res. 2018, 63, 431-442. 
24. Klimczewski, M.; Nicewicz, D. Wybrane właściwości mas włóknistych przeznaczonych na płyty HDF z dodatkiem włókien poużytkowych [Selected properties of pulp for hdf boards with the addition of post-consumer fibers (In Polish)]. Drewno 2013, 189, 89-100. [CrossRef]

25. Kronospan Kronospan 30 lat w Polsce! [30 years of Kronospan in Poland! (In Polish)]. Available online: http://biuroprasowe.kronospan.pl/71464-kronospan-30-lat-w-polsce (accessed on 1 April 2020).

26. Homanit Presentation oF Factories. Available online: https://www.homanit.org/en/company/presentation_fa ctories.php (accessed on 1 April 2020).

27. Fibre Boards. The Pfleiderer Rawboards with Large Design Potential. Available online: https://www.pfleider er.com/global-en/products/raw-wood-based-panels/fibre-boards (accessed on 1 April 2020).

28. Bakunowicz, J.K. Fabryka IKEA: Premier w Wytwórni Płyt HDF. Zakład, jak Kosmiczne Centrum [Koszki, IKEA Factory: Prime Ministry in HDF Boards Plan. A Plant Like a Cosmic Center (In Polish)]. Available online: https://poranny.pl/koszki-fabryka-ikea-premier-w-wytworni-plyt-hdf-zaklad-jak-kosmiczne-cent rum-zdjecia/ar/c3-5382674 (accessed on 1 April 2020).

29. IKEA. IKEA Industry Zbąszynek. Available online: https://www.industry.ikea.pl/index/nasze-zaklady/zbąs zynek.html (accessed on 1 April 2020).

30. GR United Kingdom: There Are Plans to Recycle Medium Density Fiberboards. Available online: https: //global-recycling.info/archives/1323 (accessed on 1 April 2020).

31. EN 326-2 Wood-Based Panels. Sampling, Cutting and Inspection. Initial Type Testing and Factory Production Control; European Committee for Standardization: Brussels, Belgium, 2010.

32. EN 326-1 Wood-Based Panels. Sampling, Cutting and Inspection. Sampling and Cutting of Test Pieces and Expression of Test Results; European Committee for Standardization: Brussels, Belgium, 1993.

33. EN 310 Wood-Based Panels. Determination of Modulus of Elasticity in Bending and of Bending Strength; European Committee for Standardization: Brussels, Belgium, 1993.

34. EN 319 Particleboards and Fibreboards. Determination of Tensile Strength Perpendicular to the Plane of the Board; European Committee for Standardization: Brussels, Belgium, 1993.

35. EN 311 Wood-Based Panels. Surface Soundness-Test Method; European Committee for Standardization: Brussels, Belgium, 2003.

36. EN 317 Particleboards and Fibreboards. Determination of Swelling in Thickness after Immersion in Water; European Committee for Standardization: Brussels, Belgium, 1993.

37. EN 382-1 Fiberboards. Determination of Surface Absorption. Test Method for Dry Process Fiberboards; European Committee for Standardization: Brussels, Belgium, 1993.

38. Gumowska, A.; Wronka, A.; Borysiuk, P.; Robles, E.; Sala, C.M.; Kowaluk, G. Production of layered wood composites with a time saving layer-by-Layer addition. BioResources 2018, 13, 8089-8099. [CrossRef]

39. EN 12460-5 Wood-Based Panels. Determination of Formaldehyde Release-Extraction Method (Called the Perforator Method); European Committee for Standardization: Brussels, Belgium, 2016.

40. Park, B.-D.; Kim, Y.-S.; Riedl, B. Effect of Wood-Fiber Characteristics on Medium Density Fiberboard (MDF) Performance. J. Korean Wood Sci. Technol. 2001, 29, 27-35.

41. Computer Desktop Encyclopedia. Available online: https://encyclopedia2.thefreedictionary.com/CIELAB (accessed on 1 April 2020).

42. Hoffmann, G. CIELab Color Space. Available online: http://docs-hoffmann.de/cielab03022003.pdf (accessed on 1 April 2020).

43. Wong, E.D.; Zhang, M.; Wang, Q.; Han, G.; Kawai, S. Formation of the density profile and its effects on the properties of fiberboard. J. Wood Sci. 2000, 46, 202-209. [CrossRef]

44. EN 622-5 Fibreboards. Specifications. Requirements for Dry Process Boards (MDF); European Committee for Standardization: Brussels, Belgium, 2010.

45. Cai, Z.; Muehl, J.H.; Winandy, J.E. Effects of panel density and mat moisture content on processing medium density fiberboard. For. Prod. J. 2006, 56, 20-25.

46. Ganev, S.; Gendron, G.; Cloutier, A.; Beauregard, R. Mechanical properties of MDF as a function of density and moisture content. Wood Fiber Sci. 2005, 37, 314-326.

47. Woodson, G.E. Properties of Medium-Density Fiberboard Related to Hardwood Specific Gravity. Tenth Part. Symp. 1976, 175-192.

48. Hwang, C.Y.; Chung-run Hse, T.F.S. Effects of recycled fiber on the properties of fiberboard panels. For. Prod. J. 2005, 55, 61-64. 
49. Xing, C.; Zhang, S.Y.; Deng, J.; Riedl, B.; Cloutier, A. Medium-Density fiberboard performance as affected by wood fiber acidity, bulk density, and size distribution. Wood Sci. Technol. 2006, 40, 637-646. [CrossRef]

50. EPF Medium Density Fibreboard. Available online: https://europanels.org/the-wood-based-panel-industry/t ypes-of-wood-based-panels-economic-impact/medium-density-fibreboard/ (accessed on 1 April 2020).

51. Trechsel, H.R.; Bomberg, M.T.; Carll, C.; Wiedenhoeft, A.C. Moisture-related properties of wood and the effects of moisture on wood and wood products. In Moisture Control in Buildings: The Key Factor in Mold Prevention, 2nd ed.; ASTM International: West Conshohocken, PA, USA, 2010; pp. 54-79. [CrossRef]

52. Carll, C.G. Review of Thickness Swell in Hardboard Siding Effect of Processing Variables; Forest Products Laboratory: USDA, Madison, WI, USA, 1996; p. 12.

53. Białecki, F.; Pohl, P.; Sydor, M. Investigations on sealing material consumption in relation with the roughness parameters of HDF boards. Electron. J. Polish Agric. Univ. Ser. Wood Technol. 2008, 11, 17.

(C) 2020 by the authors. Licensee MDPI, Basel, Switzerland. This article is an open access article distributed under the terms and conditions of the Creative Commons Attribution (CC BY) license (http://creativecommons.org/licenses/by/4.0/). 